\title{
RESENHA \\ O EXPANSIONISMO BRASILEIRO E A FORMAÇÃO DOS ESTADOS NA BACIA DO PRATA
}

\author{
Marcos Antônio Fávaro Martins ${ }^{(*)}$ \\ Universidade de São Paulo, São Paulo (SP), Brasil \\ Maria Cristina Cacciamali ${ }^{(* *)}$ \\ Universidade de São Paulo, São Paulo (SP), Brasil
}

Um dos livros brasileiros mais importantes sobre o processo de formação dos Estados na Bacia do Rio da Prata foi aquele escrito por Moniz Bandeira cujo título é "O expansionismo brasileiro e a formação dos Estados na Bacia do Rio da Prata - Da colonização à Guerra da Tríplice Aliança" (REVAN, 1998). O trabalho deriva da tese de doutorado "O Papel do Brasil na Bacia do Prata - da Colonização ao Império" defendida em 1982. O trabalho foi republicado em 2012 com o título "A Expansão do Brasil e a Formação dos Estados na Bacia do Prata".

A tese que o livro defende é que a Guerra da Tríplice Aliança (1865-870) foi o produto do processo violento de formação dos Estados nesta região e não um desdobramento da política imperial Inglesa na América do Sul, como defendido pelos historiadores revisionistas da década de 1980. Outra ideia importante do livro é que a conduta brasileira na política platina foi herdeira da política portuguesa da época colonial. O fato da independência do Brasil ter se dado por um processo de negociação, fez do Brasil continuador da tradição burocrática e política do Estado português, com impactos significativos em sua política externa.

O livro começa apresentando a determinante geográfica da expansão de Portugal além daqueles limites estabelecidos pelo Tratado de Tordesilhas: enquanto os espanhóis, partindo do Oceano Pacífico, encontraram os Andes pródigos de metais preciosos, os portugueses, partindo do oceano Atlântico não encontram ouro em suas terras e passaram a cogitar a possibilidade de anexar Potosí, que era o núcleo da mineração espanhola.

(*) Mestre, aluno do curso de doutorado do Programa Interunidades em Integração da América Latina da Universidade de São Paulo (PROLAM/USP). E-mail: <marcosfavaro84@gmail.com>.

(**) Doutora, professora da Faculdade de Economia e Administração da Universidade de São Paulo (FEA/USP); professora do Programa Interunidades em Integração da América Latina da Universidade de São Paulo (PROLAM/USP). E-mail: <cciamali@uol.com.br>. Recebido: 23.02.2015; aceito em: 18.05.2015. 
A anexação de Portugal por parte da Espanha - a União Ibérica (1580-1640) facilitou a penetração portuguesa no território espanhol. Tal união também deu ensejo para a invasão holandesa dos territórios lusitanos de ultramar. Antes da união ibérica, os holandeses eram aliados dos portugueses e inimigos dos espanhóis. A submissão de Portugal à Espanha levou o império marítimo holandês a ocupar o nordeste brasileiro e Angola. O Atlântico Sul foi com isso bloqueado aos navios ibéricos, o que prejudicou o abastecimento dos mercados brasileiros por escravos africanos. Como alternativa a esse problema, os luso-brasileiros passaram a organizar as bandeiras, que eram expedições de caráter militar cujo objetivo era o apresamento de indígenas para o trabalho escravo.

As bandeiras serviram como um elemento importante para a expansão territorial de Portugal, ocupando o espaço das reduções jesuíticas e penetrando como uma cunha no flanco sul do domínio espanhol. Mais importante que as bandeiras, era a iniciativa para o domínio da foz dos grandes rios (o Amazonas e o Prata), pois estas eram os únicos acessos eficientes e seguros para o interior do continente a partir Atlântico.

Portugal entrava nesta segunda metade do século XVII demasiadamente fragilizado. Em 1640, o Duque de Bragança liderou a rebelião que rompeu os laços de Portugal com a Espanha, o que só foi possível com o apoio inglês. Começava então uma fase de disputas territoriais com a Espanha e de vassalagem com a Inglaterra. A Inglaterra passava a ser um importante elemento da política portuguesa, pois era ela o destino final das riquezas exploradas por Portugal, ao mesmo tempo que ela oferecia importante apoio para os portugueses em suas campanhas de conquista na América do Sul.

Na bacia do Rio Amazonas, por exemplo, a Inglaterra, para alijar a França da América do Sul, reconheceu a soberania de Portugal sobre a Amazônia. Tratava-se de uma velha aspiração portuguesa, uma vez que, no ano de 1616, foi construído na foz do Amazonas o Forte Presépio, que garantia aos portugueses a posse de toda a extensão da bacia amazônica. O domínio da foz do Rio Amazonas permitiu que os luso-brasileiros avançassem Amazônia adentro, tomando territórios não ocupados do Império Espanhol e encantonando os franceses no território da atual Guiana Francesa.

Mais importante para Portugal era a tomada de uma das margens da foz da bacia do Rio da Prata e, no ano de 1643, Salvador de Sá propôs no conselho ultramarino português a tomada da cidade de Buenos Aires. Portugal então estendeu sua cadeia de bases navais para o sul do continente, fundando em 1660 a Villa de São Francisco; ocuparam em 1675 a Ilha de Santa Catarina; e em 1676 a Zona da Laguna.

Em 1680, essa cadeia de bases ganhou a sua última fortaleza, a Colônia de Sacramento que, localizada próxima a Buenos Aires, objetivava servir de base para sua invasão. Sacramento também dava a Portugal o controle da Banda Oriental e possibilitava o controle do trafego de navios sobre os rios da bacia. Dado esse quadro hostil, poucos meses depois de sua fundação, a Colônia de Sacramento foi atacada e destruída pelo governo de Buenos Aires. Era o começo de um século de guerras pelo domínio da foz do rio da Prata. Até o ano de 1777, o território da banda oriental trocou de lado sucessivas vezes em frequentes campanhas militares. No Tratado de Madri (1750), a Espanha abriu mão do Território das Missões para manter o domínio sobre a foz do rio e, em 1777, com o tratado de Santo Ildefonso, manteve-se o domínio espanhol sobre as Missões e sobre 
Sacramento. Mas vivia-se as últimas décadas do império espanhol, e o processo de independência não encerraria as disputas pelo domínio desses territórios.

Em maio de 1810, tem início o processo revolucionário que libertaria do julgo da Espanha as províncias do rio da Prata. Seu líder, José Artigas (1764-1850), pretendia estender a revolução para a banda oriental dos territórios hispânicos e depois disso exportar a revolução para o Rio Grande de São Pedro, o que, naturalmente, preocupou as autoridades portuguesas. É importante lembrar que a Europa, estavam sob o jugo dos exércitos napoleônicos e a corte portuguesa estava alocada no Rio de Janeiro. Para impedir que a revolução de Artigas chegasse ao sul dos domínios portugueses na América, bem como para retomar os seus objetivos geopolíticos, Dom João VI invadiu Montevidéu com forças terrestres no ano de 1811.

Para os ingleses, não era interessante que os portugueses monopolizassem o acesso da bacia e, por pressão deles, as forças de Dom João VI se retiraram em 1812. Em 1815, os revolucionários de Artigas chegaram a Montevidéu e as forças portuguesas voltaram a intervir em 1816, sendo retiradas em 1817. Se iniciava, portanto, mais um período de expedições militares luso-brasileiras na Banda Oriental.

A partir de sua metade, o livro começa a tratar dos processos de emancipação das colônias. Com a independência, o Brasil replica a burocracia do Estado português. A continuidade da vigência das instituições representou a continuidade de uma política externa agressiva, marcada pelo intervencionismo e pelas ambições expansionistas.

Para garantir o seu domínio sobre a foz do rio da Prata, bem como para conter a exportação da revolução republicana, o Império Português anexou a banda Oriental em 1821, dando-lhe o nome de Província de Cisplatina. A questão da cisplatina perdurou com a independência do Brasil e ela redundou na primeira grande guerra que o Brasil independente lutou, a "Guerra da Cisplatina" (1825-1828).

Para consolidar a anexação da nova província, D. João VI enfrentou grandes dificuldades. Tal ocupação era impopular dentro do próprio Rio de Janeiro, e as sublevações internas brasileiras tiravam a sua força. A anexação também não contava com o apoio nem da Inglaterra, nem da Espanha, que temiam domínio brasileiro da Bacia. Buenos Aires também organizara um Estado federativo, as Províncias Unidas do Rio da Prata, que conteria temporariamente o ímpeto expansionista do Brasil.

Em todas as ocupações luso-brasileiras da Banda Oriental, os interesses de Portugal mesclaram-se com os interesses dos estancieiros do Rio Grande e São Pedro, que adentravam o território oriental para a pilhagem do gado. Em 1820, as pastagens uruguaias estavam devastadas e a sociedade submetida a um estado de violência generalizada. $\mathrm{O}$ descontentamento popular com a ocupação brasileira de 1821 foi o prelúdio da formação do Uruguai. Em 1825, Juan Antonio Lavalleja (1784-1853) partiu de Buenos Aires e, seguido por 32 homens, atravessou o rio Uruguai e promoveu a sublevação em Montevidéu, que deu origem à Guerra da Cisplatina.

Lavalleja contou com apoio de Frutuoso Rivera (1784-1854), um antigo colaborador da ocupação luso-brasileira, que mudou de lado e colocou suas tropas ao serviço da causa uruguaia. O exército de Lavalleja aumentara de trinta e dois homens para seis 
divisões. As Províncias Unidas do Rio da Prata, então governada por Rivadavia (17801845), entraram na guerra em apoio ao Uruguai, o que levou Dom Pedro I (1798-1834) a bloquear os acessos à bacia do Rio da Prata, medida que incomodou tanto a Inglaterra como os EUA, preocupados com o fluxo de mercadorias na região.

A guerra de corso promovida por Buenos Aires contra o Império, o impasse da campanha terrestre, a pressão inglesa e estadunidense pelo fim das hostilidades levaram a independência do Uruguai. Visando o equilíbrio de poder na bacia do Prata, a Inglaterra, pelos trabalhos do Lord Ponsonby (1770-1855), pôs fim à guerra, fundando um Estado tampão entre o Brasil e Buenos Aires, o Uruguai. Dada a sua crise interna, as Províncias Unidas do Rio da Prata entraram em colapso e se balcanizou em 1826.

O autor trata na sequência da iniciativa de Buenos Aires de reconstruir o Vice-Reinado do Rio da Prata. A Argentina era então uma constelação de pequenos Estados divididos por complexas questões aduaneiras. Um grande momento para a unificação nacional ocorreu com a ascensão de Juan Manuel Rosas (1793-1877) ao poder. Sua administração (1828-1852) conseguiu organizar o país dentro de um arranjo federativo (a Confederação Argentina), e tinha a intenção de ampliar o novo Estado, reconstruindo o Vice-Reinado do Rio da Prata. Este projeto, que Rosas deu o nome de "Sistema Americano", envolvia a submissão do recém-fundado Uruguai, da Bolívia e do Paraguai.

No caso uruguaio, Rosas depôs Frutuoso Rivera e pôs no seu lugar um aliado, Manuel Oribe (1835-1838). Para tanto, contou com o apoio do Brasil, com quem Rivera deteriorara suas relações, ao anunciar o seu projeto federativo de um Uruguai Maior, com a incorporação de Corrientes e Rio Grande e São Pedro. No entanto, o projeto rosista era também antagônico aos objetivos brasileiros, porque cortava as comunicações brasileiras pelo rio Paraguai e, no limite, minava a pretensão brasileira de domínio da bacia Platense. Uma vez vencido Rivera, era a vez de Rosas e Oribe enfrentarem o Brasil.

A ameaça da Argentina de incorporar o Uruguai era eminente na década de 1940 e o sucesso político de Rosas aumentaria a sua influência sobre o Paraguai e a Bolívia. Ameaçava ainda a posição brasileira a simpatia inicial conquistada por Rosas junto à Inglaterra e França, uma vez que a pacificação social promovida por Rosas tornava viável o comércio internacional. Sem o apoio dessas duas potências, o Brasil reconheceu a independência do Paraguai, dificultando a sua incorporação ao Sistema Americano.

Rosas padeceu com o desgaste político, uma vez que os princípios federalistas do seu modelo ruíram já na década de 1840 , por conta da pressão que a elite portenha fazia em prol do centralismo. Rosas rompeu com alguns dos seus antigos aliados, entre eles, Justo José Urquiza (1801-1870). No Uruguai, a política de Oribe de libertação dos escravos e a contenção aos assaltos de gado foram o estopim da Guerra com o Brasil. Em 1850, foram rompidas as relações do império com a Confederação Argentina e, com apoio das tropas de Urquiza, o exército brasileiro depôs Rosas em 1852 na batalha de Caseros. Era o fim de um ambicioso projeto geopolítico, que jamais conseguiu ser realizado.

Em uma tentativa de consolidar o seu governo, Urquiza se aproximou do Império Brasileiro, abriu o rio da Prata para a livre navegação e reconheceu a independência do Paraguai. Em uma tentativa de retomar a organização federativa da república com o 
Acordo de São Nicolás (1852), Urquiza promoveu a nova secessão do país: a província de Buenos Aires não aceitava perder seus direitos aduaneiros, motivo pelo qual declarou independência. Buenos Aires ficaria separada da confederação até 1859.

Da queda de Rosas até 1870, o Brasil se configurava como o principal Estado platino: a Argentina ainda era um Estado sem coesão interna, o Paraguai, ainda que organizado e próspero, possuía pouca projeção internacional, enquanto que o Uruguai estava dilacerado por disputas internas, pelas intervenções militares brasileiras e pela ruína de sua economia.

O Brasil herdara a estrutura de Estado de Portugal o que lhe permitiu atuar de maneira organizada no seu entorno estratégico. Contava com um serviço diplomático competente e extenso, e forças armadas organizadas e em número suficiente para a política de potência. Neste particular, cabe destacar a atuação da Marinha de Guerra que conseguia bloquear o rio da Prata, causando transtornos ao comércio da região.

A Argentina só vai se constituir como Estado a partir de 1861, com a Batalha de Pavón, que alijou Urquiza do poder e instituiu Bartolomé Mitre (1821-1906) como novo presidente. Mitre unificou e organizou o Estado que, a partir de então, passou a se chamar República Argentina. A partir de então, a Argentina passou a ter um peso maior na política internacional, passou a atuar no Uruguai, onde, em concordância com o Brasil, apoiava o governo de Bernardo Berro (1803-1868). Berro foi sucedido por Atanasio Aguirre (1801-1875), que rompeu as alianças com o Brasil e a Argentina.

O Uruguai estava isolado entre a Argentina e o Brasil, o que o fazia procurar apoio no Paraguai que, a partir da administração de Carlos Antônio Lopez (1844-1862), passava a se modernizar e ter relações internacionais mais expressivas, buscando atrair investimentos da Inglaterra e da França. Carlos Antônio Lopez foi substituído pelo seu filho, Francisco Solano Lopez (1827-1870) que organizou as forças armadas paraguaias e planejou constituir um poderoso Estado, com condições de fazer frente ao Brasil.

Em fins de 1864, tropas brasileiras invadiram novamente o Uruguai, para proteger as propriedades brasileiras da sublevação popular e para depor Aguirre, anulando com isso a iniciativa paraguaia e uruguaia de fundar uma terceira força política na bacia do rio da Prata. A intervenção, que teve apoio argentino, levou a resposta armada do Paraguai: tropas de Solano Lopez invadiram o Brasil e a Argentina, dando início à Guerra do Paraguai (1865-1870).

Assim sendo, a conclusão maior a que o livro chega diz respeito às origens da Guerra do Paraguai. A guerra, que dizimou a população masculina do Paraguai e arruinou a economia brasileira, foi produto do processo violento de formação dos Estados na bacia do rio da Prata, cuja força dinâmica era o expansionismo do Brasil.

A Inglaterra, que apoiou conforme os seus interesses o Império Português em questões anteriores, priorizava pela manutenção da livre navegação na bacia do rio da Prata para o desenvolvimento do comércio, o que não acontecia em uma situação de guerra. Além disso, o império inglês possuía investimentos respeitáveis no Paraguai, o que tornava a guerra, pelo menos a princípio, desinteressante para os seus interesses. 
Já, para os atores regionais, os motivos para a luta foram muito mais evidentes. A última intervenção armada do Brasil no Uruguai (1864), a que levou a deposição de Aguirre, minou o projeto dos Lopez, de conseguir por vias diplomáticas um Estado maior. Tanto para recém-fundada Argentina quanto para o Brasil, o sucesso paraguaio levaria a formação de uma terceira força no cenário, o que constituía uma ameaça perigosa, principalmente para a Argentina.

Depois da guerra, a crise entre Brasil e Argentina ressurgiu. A ocupação militar por brasileiros no Paraguai causou o constrangimento da Argentina, que intencionava anexar o país destruído. A Argentina agora era organizada e próspera, principalmente pelo fato de seus estancieiros terem fornecido os víveres para as tropas aliadas em luta. Isso ocasionou a ascensão da Argentina e a decadência do Brasil, e encerrou um longo ciclo da história diplomática sul-americana.

Denso e muito bem escrito, o livro do professor Bandeira apresenta uma contribuição ímpar para a História das Relações Internacionais da América Latina. O valor que o autor dá aos fatores geopolíticos e para a análise de longo prazo do processo histórico redobram o valor intelectual do trabalho. Sem dúvida, essa é uma leitura que não deve faltar para os estudiosos das Relações Internacionais da América Latina.

\section{BIBLIOGRAFIA}

BANDEIRA, Luiz Alberto Moniz. OExpansionismo brasileiro e a formação dos Estados na Bacia do Prata: Argentina, Uruguai e Paraguai. Da colonização à Guerra da Tríplice Aliança. 3. ed. Rio de Janeiro: Revan; Brasília: Editora da Universidade de Brasília, 1998. 